\title{
GmbZIP1 negatively regulates ABA-induced inhibition of nodulation by targeting GmENOD40-1 in soybean
}

Shimin $\mathrm{Xu}^{\dagger}$, Shanshan Song ${ }^{\dagger}$, Xiaoxu Dong, Xinyue Wang, Jun Wu, Ziyin Ren, Xuesong Wu, Jingjing Lu, Huifang Yuan, Xinying Wu, Xia Li and Zhijuan Wang ${ }^{*}$ (1)

\begin{abstract}
Background: Abscisic acid (ABA) plays an important role in plant growth and adaptation through the ABA signaling pathway. The ABA-responsive element binding (AREB/ABF) family transcriptional factors are central regulators that integrate $A B A$ signaling with various signaling pathways. It has long been known that $A B A$ inhibits rhizobial infection and nodule formation in legumes, but the underlying molecular mechanisms remain elusive.

Results: Here, we show that nodulation is very sensitive to ABA and exogenous ABA dramatically inhibits rhizobial infection and nodule formation in soybean. In addition, we proved that GmbZIP1, an AREB/ABF transcription factor, is a major regulator in both nodulation and plant response to ABA in soybean. GmbZIP1 was specifically expressed during nodule formation and development. Overexpression of GmbZIP1 resulted in reduced rhizobial infection and decreased nodule number. Furthermore, GmbZIP1 is responsive to ABA, and ectopic overexpression of GmbZIP1 increased sensitivity of Arabidopsis plants to ABA during seed germination and postgerminative growth, and conferred enhanced drought tolerance of plants. Remarkably, we found that GmbZIP1 directly binds to the promoter of GmENOD40-1, a marker gene for nodule formation, to repress its expression.
\end{abstract}

Conclusion: Our results identified GmbZIP1 as a node regulator that integrates ABA signaling with nodulation signaling to negatively regulate nodule formation.

Keywords: ABA, Nodulation, GmbZIP1, GmENOD40-1, Soybean

\section{Background}

Root nodules are specialized root organ in leguminous plants developed under low nitrate conditions, where legumes and nitrogen-fixing bacteria (rhizobia) form a symbiotic relationship. In symbiotic nodules, legume plants provide bacteria with carbohydrates and energy for its growth and survival, conversely bacteria supply the plants with $\mathrm{NH} 3$ converted from

\footnotetext{
* Correspondence: wangzj@mail.hzau.edu.cn

'Shimin Xu and Shanshan Song contributed equally to this work.

National Key Laboratory of Crop Genetic Improvement, College of Plant Science and Technology, Huazhong Agricultural University, Wuhan, Hubei 430070, P.R. China
}

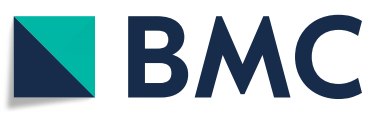

(c) The Author(s). 2021 Open Access This article is licensed under a Creative Commons Attribution 4.0 International License, which permits use, sharing, adaptation, distribution and reproduction in any medium or format, as long as you give appropriate credit to the original author(s) and the source, provide a link to the Creative Commons licence, and indicate if changes were made. The images or other third party material in this article are included in the article's Creative Commons licence, unless indicated otherwise in a credit line to the material. If material is not included in the article's Creative Commons licence and your intended use is not permitted by statutory regulation or exceeds the permitted use, you will need to obtain permission directly from the copyright holder. To view a copy of this licence, visit http://creativecommons.org/licenses/by/4.0/ The Creative Commons Public Domain Dedication waiver (http://creativecommons.org/publicdomain/zero/1.0/) applies to the data made available in this article, unless otherwise stated in a credit line to the data. mand of legume plants [1-3].

The process of nodulation is initiated by a reciprocal and specific crosstalk between legumes and rhizobia. Under low nitrogen conditions, legume roots secrete flavonoid molecules into rhizosphere, which induce compatible rhizobia to synthesize and release signaling molecules called Nod factors (NFs) [4-6]. NFs are perceived by Lysine motif receptor-like kinases (LysM) receptors (NFRs) located at plasma membrane of the epidermal cells of roots and root hairs. These NF receptors include NF Perception (NFP) in M. truncatula, NF Receptors 1 and $5(\mathrm{NFR} 1 / 5)$ in L. japonicus, SYM10/ 
SYM2 in P. sativum (pea) and NFR $1 \alpha / \beta$ and NFR $5 \alpha / \beta$ in G. $\max$ (soybean) [7-11]. The perception of NFs by these LysM receptors triggers a signaling cascade (the nodulation signaling) and a variety of cellular events to activate rhizobial infection and nodule formation. The key events following the NF perception are calcium spiking in the cytoplasm of infected root hair cells and transducing of the calcium signal to the nucleus by Does Not Make Infections 1 and 2 (DMI1 and DMI2) and Nuclear-localized cyclic nucleotide-gated channels (CNGC15) [12-14]. Calcium oscillations in the nucleus is decoded by Calcium and Calmodulin-dependent Kinase (CCaMK in Lotus and DMI3 in Medicago) that form complex with CYCLOPS to activate a set of transcriptional factors $[15,16]$. These transcriptional factors include two GRAS domain transcriptional regulators [17-21], including Nodulation Signaling Pathway1 (NSP1) and NSP2, which can form a complex to directly activate expression of Nodule Inception (NIN), Ethylene Response Factor Required for Nodulation1 (ERN1) and Early Nodulin 11 (ENOD11) [22, 23].

Phytohormones play a central role in symbiotic nodulation. Among them, cytokinin (CK) and auxin positively regulate symbiotic nodulation [24-29], while other hormones, such as jasmonate (JA), salicylic acid (SA), gibberellic acid, ethylene and ABA negatively regulate both rhizobial infection and nodule organogenesis [30]. Although ABA is well-known for its anti-stress effects in plants [31], researchers have also identified a negative role of ABA in nodulation of legumes. Exogenous application of $\mathrm{ABA}$ strongly reduced nodule number, while the treatment of Abamine, a specific ABA biosynthesis inhibitor increased nodule number [32-36]. ABA inhibited NF-induced calcium spiking in M. trunctula, suggesting that $\mathrm{ABA}$ affects nodulation at very early stage [35]. In L. japonicus, ABA treatment dramatically decreased the number of curled root hairs and the infection threads [33]. Consistent with these results, the induction of nodulin genes by NFs or rhizobia, such as Rhizobium-induced Peroxidase (RIP) and ENOD11, was abolished by ABA treatment [35]. Further genetic evidence that blocking the $\mathrm{ABA}$ signaling by overexpression of the Arabidopsis dominant negative allele abi1-1 increased nodulin genes expression and subsequent nodule number demonstrates an inhibitory role of $\mathrm{ABA}$ in nodulation [35]. It appears that ABA suppressed the cytokinin-activated expression of a nodulation gene ENOD40 that is involved in nodule formation in root cortex [35], although the detailed mechanisms by which ABA inhibits nodulation and cross-talks to cytokinin are still to be elucidated.

ABA exerts its function through the canonical ABA signaling, which is a dynamic process that is initiated by the binding of ABA to the ABA receptors (the PYR1/PYLs/
RCAR protein family), and involved the rapid transmission of the signal by group A protein type $2 \mathrm{C}$ phosphatases (PP2Cs) and sucrose nonfermenting-1-related protein kinase class 2 (SnRK2s) to the nucleus followed by ultimate activation of transcription factors resulting in altered expression of target genes [37-42]. ABA-responsive element (ABRE) binding protein/ABRE binding factors (AREB/ABF) transcription factors are responsible for the expression of most of the target genes, which are also known as $A B R E / A B F$ regulon. In plants, these $A R E B / A B F$ transcription factors are basic region/leucine zipper (bZIP) class family proteins and can bind to the ABRE cis element in the promoters of ABA-responsive genes [43-45]. As a result, $\mathrm{ABA}$ can help to regulate plant response to abiotic stress [43-45]. Thus, the AREB/ABF transcription factors play a crucial role in controlling the activity of genes that regulate various aspects of plant response.

The inhibitory effect of ABA on soybean nodulation has been reported [32, 46-48]. It has been shown that ABA treatment markedly reduced production of isoflavonoid compounds, such as daizdzein, genistein and coumestrol [32], thereby leading reduced rhizobial infection. However, no significant progress has been made in how ABA affects soybean nodulation since then. Based on the current evidence, soybean has the canonical ABA signaling, which consists of PYR1/PYLs receptors for ABA, PP2Cs, SnRKs and AREB/ABF transcription factors. For GmbZIPs, there are 160 GmbZIP genes identified in soybean genome, and few of them (e.g. GmbZIP1 and GmbZIP2) has been functionally analyzed for their role in ABA response and stress tolerance $[49,50]$. However, the role of the AREB/ABF transcription factors and the molecular mechanism by which ABA interplays with nodulation signaling remain completely unknown. In this study, we analyzed the effects of ABA on soybean growth and nodulation. We identified GmbZIP1, a soybean homolog of Arabidopsis AREB1, as a positive regulator of $A B A$ response, but a negative regulator of soybean nodulation. GmbZIP1 was induced by ABA and ectopic expression of GmbZIP1 in Arabidopsis enhanced ABA sensitivity and plant tolerance to drought. Importantly, GmbZIP1 was highly expressed in nodule, and overexpression of GmbZIP1 resulted in reduced nodulation. Furthermore, we found that GmbZIP1 directly bound to and repressed the expression of GmENOD401. These findings reveal for the first time the interplay between ABA and nodulation signal transduction pathway that fine tunes rhizobial infection and nodule formation in soybean.

\section{Results}

\section{ABA inhibits nodulation in soybean}

To assess the role of ABA during symbiotic nodulation in soybean, we first analyzed ABA effects on plant 
growth and nodule formation. Six day-old soybean seedlings germinated on agar media were transferred onto Jensen's plates [51] supplemented with $0,0.5,1$ or $10 \mu \mathrm{M}$ ABA and inoculated the plants with $B$. diazoefficiens USDA110. Eighteen days after ABA treatment and rhizobial inoculation, plant height, lateral root number and the number of root nodules were evaluated. As shown in Fig. 1a and b, shoot growth of the soybean seedlings was sensitive to ABA. Shoot growth was promoted by low concentration $(0.5 \mu \mathrm{M})$ of $\mathrm{ABA}$ but was inhibited by high concentration $(10 \mu \mathrm{M})$ of ABA. In comparison, lateral root formation of soybean seedlings showed different pattern in the conditions of ABA treatment (Fig. 1c and d). Lateral root formation of the plants treated with low concentrations $(0.5$ and $1 \mu \mathrm{M})$ of $\mathrm{ABA}$ was comparable to that of the control plants, however, lateral roots were significantly increased when treated with high concentration $(10 \mu \mathrm{M})$ of ABA (Fig. 1c and d). In sharp contrast, nodulation was quite sensitive to $A B A$ in soybean and nodule number strongly diminished with increased concentrations of ABA (Fig. 1c and e). The nodule number per plant under $0.5 \mu \mathrm{M}$ ABA treatment was reduced to half of the control plants, and the nodule number was nearly completely abolished in the presence of $10 \mu \mathrm{M}$ ABA. These results indicate that root nodule is the most sensitive organ of soybean to ABA during growth and development, and ABA plays a negative regulatory role in soybean nodulation.
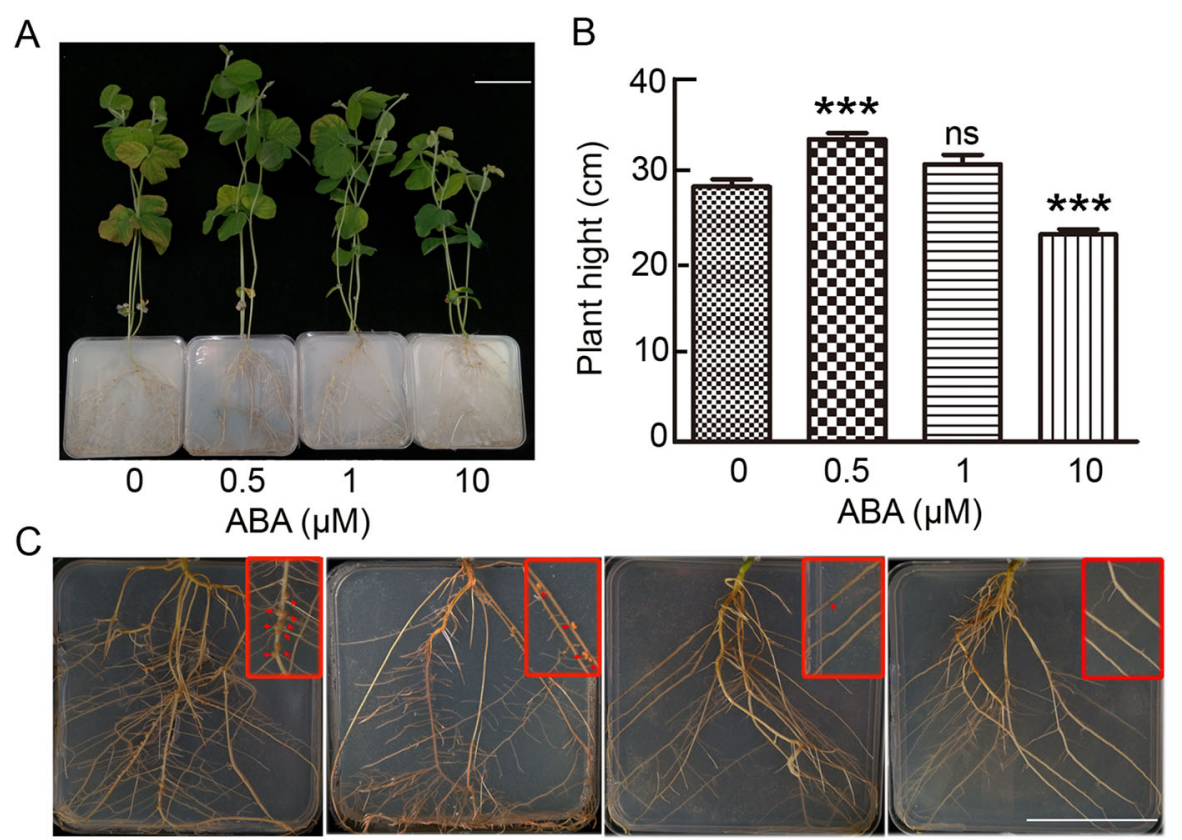

0

0.5

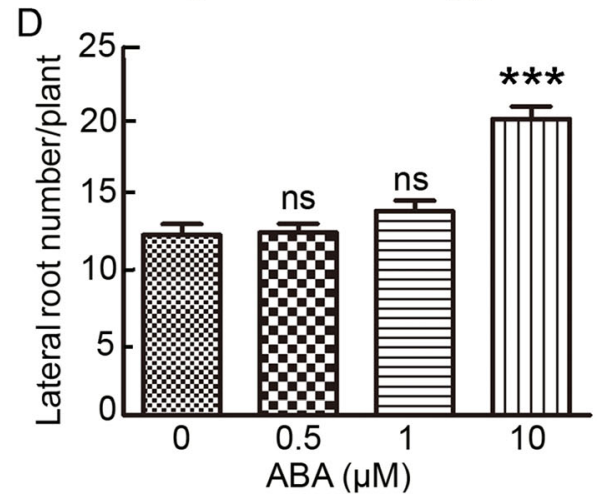

1

$10 \mathrm{ABA}(\mu \mathrm{M})$

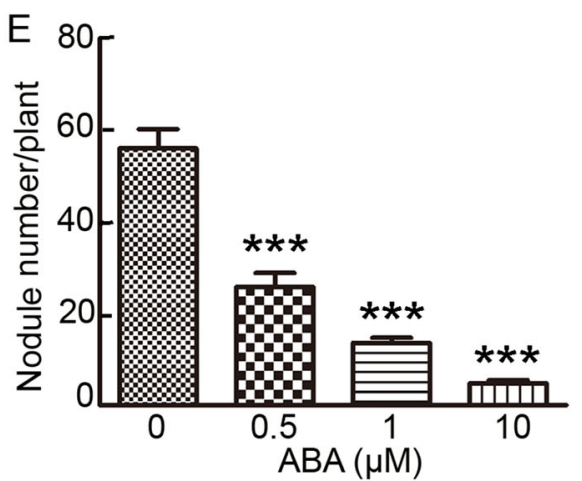

Fig. 1 Exogenous $A B A$ treatment reduces nodule number in soybean. a The phenotype of the aerial part of soybean treated with $0,0.5,1$ or 10 $\mu \mathrm{M}$ ABA; Bar=7 cm; $\mathbf{b}$ Comparison of plant height of soybean with different concentration of ABA; $\mathbf{c}$ The phenotype of root and nodule of soybean with different concentration of $A B A$; $\mathbf{d}$ Comparison of primary lateral roots number of soybean treated with different concentration of $\mathrm{ABA}$; e Comparison of root nodule number of soybean treated with different concentration of $\mathrm{ABA}$. Bar $=7 \mathrm{~cm}$. Values are means $\pm \mathrm{SD}$. ${ }^{* *}, P<$ 0.001 and $n s, P>0.05$. 


\section{ABA inhibits Rhizobial infection and NF signaling}

The nodule formation begins with the reciprocal recognition between legume plant and rhizobia, which leads to the formation of infection foci [1]. To test if ABA affects rhizobial infection, we analyzed the number of infection foci with or without ABA treatment. In the presence of $10 \mu \mathrm{M} \mathrm{ABA}$, the number of infection foci per plant was dramatically reduced compared with that of plant without ABA treatment (Fig. 2a and b), suggesting that ABA inhibits the rhizobial infection in soybean.

The reciprocal recognition of legume plant and rhizobia activates downstream signaling events, leading to rhizobia-specific infection and nodule formation [1]. To test whether ABA affects rhizobial infection by interrupting nodulation signaling, we analyzed the transcript levels of the nodulation marker gene GmENOD40-1 with or without ABA treatment. In the presence of rhizobia but without ABA treatment, GmENOD40-1 expression was highly induced by rhizobia at 3 DAI, but with ABA treatment, the induction of GmENOD40-1 was significantly reduced (Fig. 2c). The results indicate that ABA negatively regulates early nodulation through affecting the NF signaling transduction pathway.

\section{Phylogenetic and expression analysis of $A R B E$ family genes in soybean}

$\mathrm{AREB} / \mathrm{ABF}$ transcription factors are the central regulators of $\mathrm{ABA}$ responses in plants [43-45]. We wondered if the AREB transcription factors are involved in ABA-mediated suppression of soybean nodulation. AREB family genes encode the group A bZIP transcription factors and there are 28 group A members in soybean genome [49]. To search for the AREB transcriptional factors that involved in nodule organogenesis, we analyzed the evolutionary relationships between soybean and Arabidopsis. Similar to Arabidopsis [52], the 28 group A members in soybean can be classified in four distinct subgroups. Among them, GmbZIP11/ GmbZIP1 [50] (thereafter GmbZIP1), GmbZIP29, GmbZIP44 and GmbZIP50 are classified into the same clade with AtABF1-AtABF4 (Fig. 3a), which function in the ABA-mediated abiotic stresses response [43-45], while GmbZIP61, GmbZIP84, GmbZIP91, GmbZIP96 and GmbZIP129 are grouped in the same branch as Arabidopsis ABI5 (Fig. 3a), which regulates $\mathrm{ABA}$-mediated seed maturation and seed germination [53]. The result suggests potential function of these GmZIP transcription factors in ABA response in soybean.
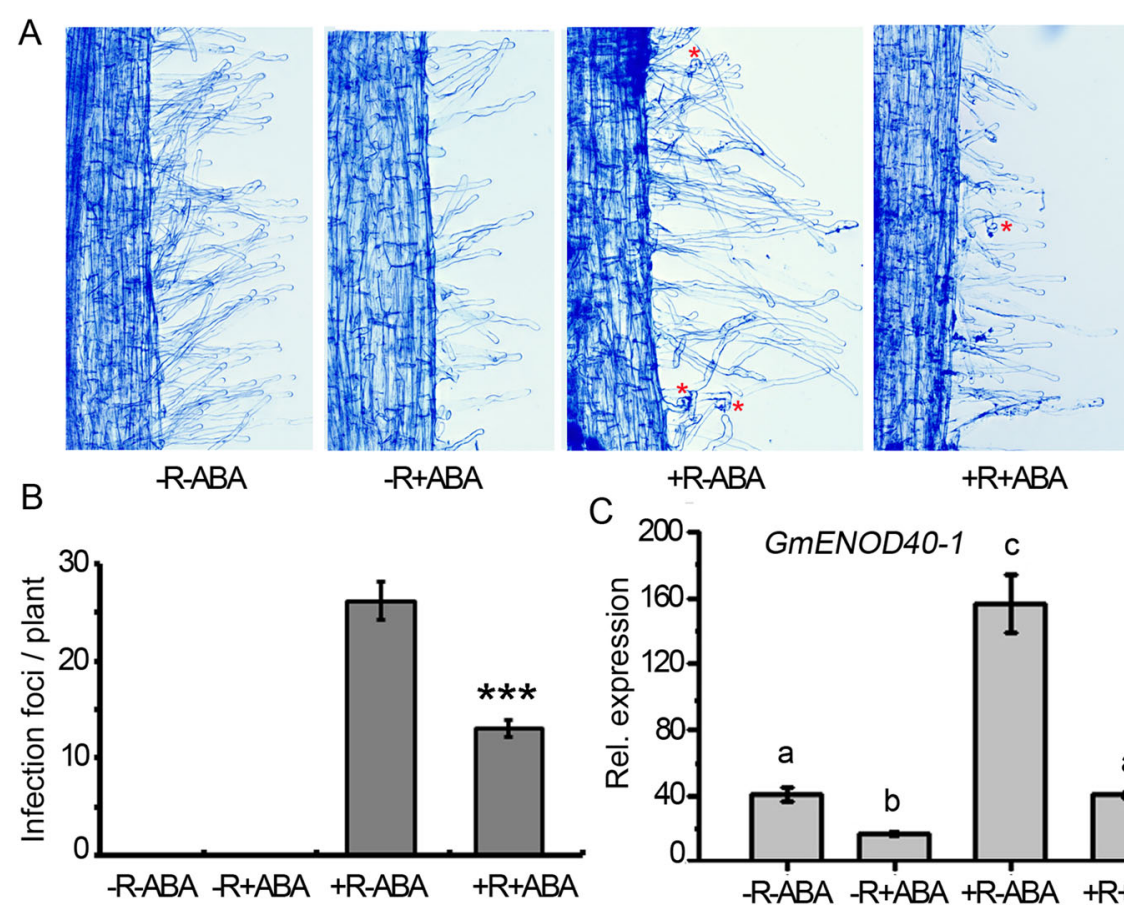

$+\mathrm{R}-\mathrm{ABA}$

$+\mathrm{R}+\mathrm{ABA}$

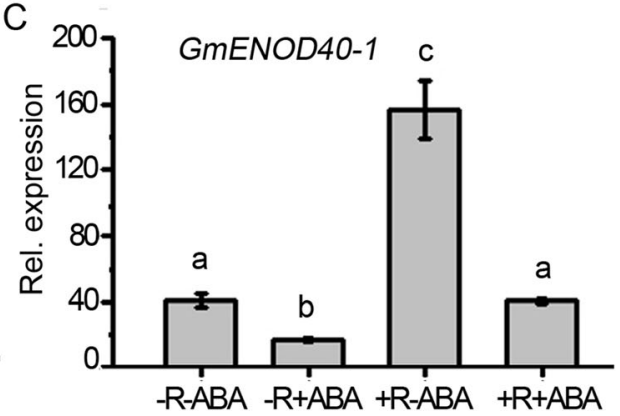

Fig. $2 A B A$ inhibits reciprocal recognition of soybean and rhizobia. a Curled root hair of roots with $A B A$ and rhizobia treatment. The asterisk marks the curled root hair at 7 day after inoculation with rhizobia; $\mathbf{b}$ The infection foci number per plant ( $n=6)$. Values are means \pm SD. $* * * P<$ 0.001; c Expression of GmENOD40-1 in the treatment of ABA and/ or rhizobia. The GmENOD40-1 was detected in roots at 3 DAI with USDA110. -R-ABA: treatment without rhizobia or $A B A$; $-R+A B A$ : treatment without rhizobia but with $A B A$; +R-ABA: treatment with rhizobia but no ABA; $+R+A B A$ : treatment with both rhizobia and $A B A$ 


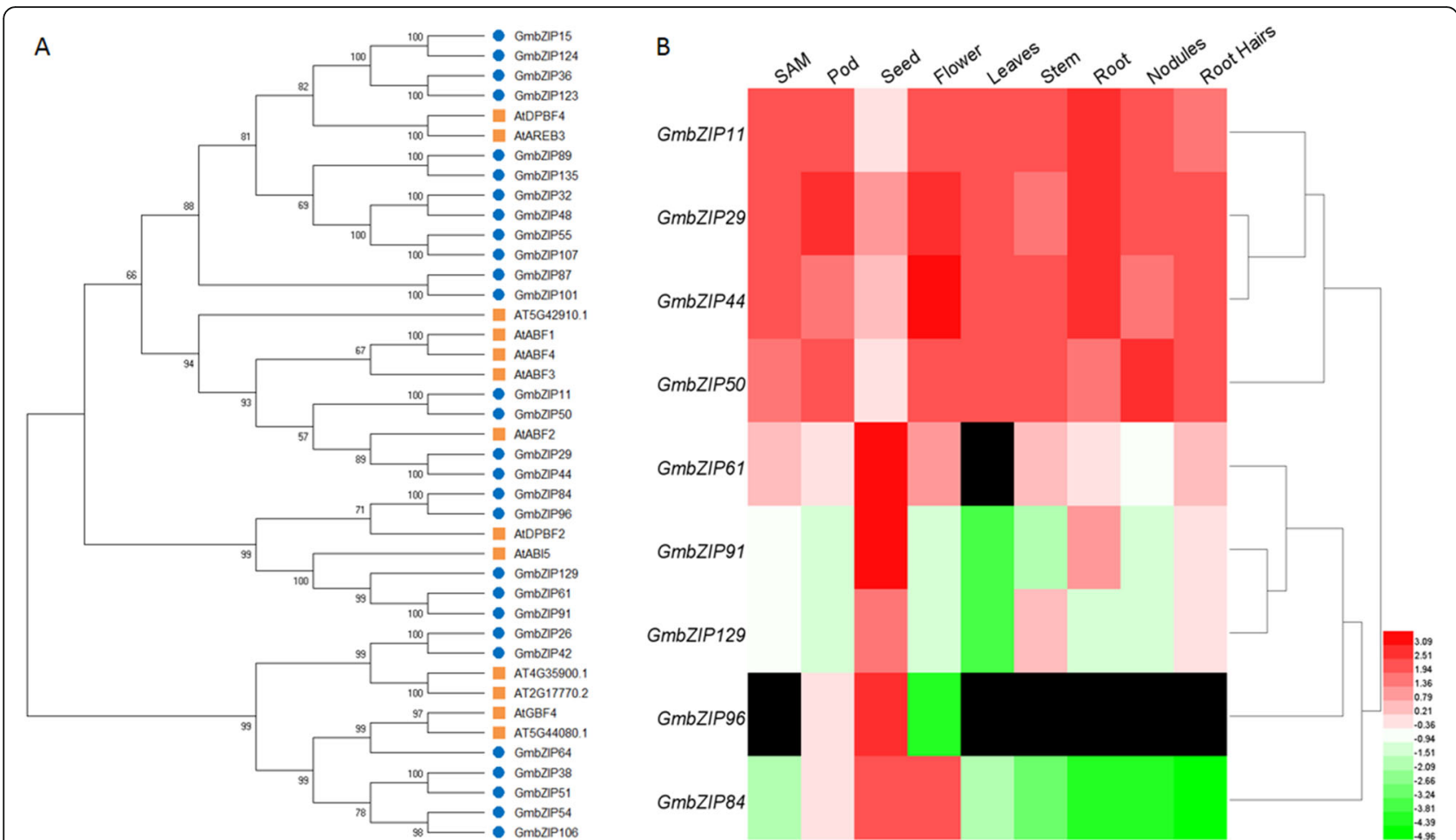

Fig. 3 Phylogenetic and expression analysis of soybean AREB family genes. a Phylogenetic analysis of the group A bZIP family members in soybean and Arabidopsis. The amino acid sequences of the group A bZIP family member were used for the alignment, and the phylogenic neighbor-joining tree was constructed using MEGA5 phylogenetic analysis software. b Expression level analysis of AREB family gene members from public data (http://soybase.org)

To find out the candidate GmAREB genes associated with nodulation, we analyzed the expression levels of GmAREB genes in different tissues and organs using RNA sequencing (RNA-Seq) data obtained from SoyBase [54] (http://soybase.org/). Among these GmAREB genes, GmbZIP129 was nearly undetectable in all the tissues, four of them including GmbZIP61, GmbZIP84, GmbZIP91, GmbZIP96 were predominantly expressed in seed, which are similar to their homologous gene $A B I 5$ in Arabidopsis [55]; and four genes including GmbZIP1, GmbZIP29, GmbZIP44 and GmbZIP50 were mainly expressed in flower and vegetative tissues including root hair and mature nodules (Fig. 3b). These data suggest that GmbZIP1, GmbZIP29, GmbZIP44 and GmbZIP50 may be involved in ABA-mediated nodule development in soybean.

\section{GmbZIP1 is predominantly expressed during nodule formation and nodule development}

To identify the GmAREB gene(s) that specifically function(s) in soybean nodulation, we performed qPCR to validate the expression patterns of GmbZIP1, GmbZIP29, GmbZIP44 and GmbZIP50 in soybean. Indeed, these four genes were differentially expressed in the tested tissues/organs including mature nodule at 28 DAI (Fig. 4a-d), suggesting diverse roles of these four
GmAREB genes during soybean growth and development. Among them, GmbZIP44 and GmbZIP50 were expressed at the highest levels in root but lower in leaf, stem and nodule (Fig. 4c and d), while GmbZIP1 and GmbZIP29 were expressed in all the tissues with the highest levels in nodule (Fig. 4a and b). Notably, GmbZIP1 was predominantly expressed in nodule with very low or no expression in other organs, and its expression level in mature nodule was much higher than other GmbZIP genes (Fig. 4a). These results suggest that GmbZIP1 may play a major and specific role in soybean nodule development.

To further examine the expression pattern of GmbZIP1 during nodule formation and nodule development, we performed a histochemical analysis to test the promoter activity of GmbZIP1 using the GUS ( $\beta$-glucuronidase) gene as a reporter. To do this, the $3 \mathrm{~kb}$ fragment upstream of ATG of GmbZIP1 was fused to the gusA gene and the resulting GmbZIP1pro:GUS construct was used for hairy root transformation and subsequent rhizobial nodulation. Histochemical analysis of GmbZIP1pro:GUS transgenic hairy roots was conducted at the specified stages of nodulation. High GUS activity was observed in nodule primordium and GUS activity was strongest in the cells at the base of nodule primordium (Fig. 4e). A high level of GUS activity was mainly 


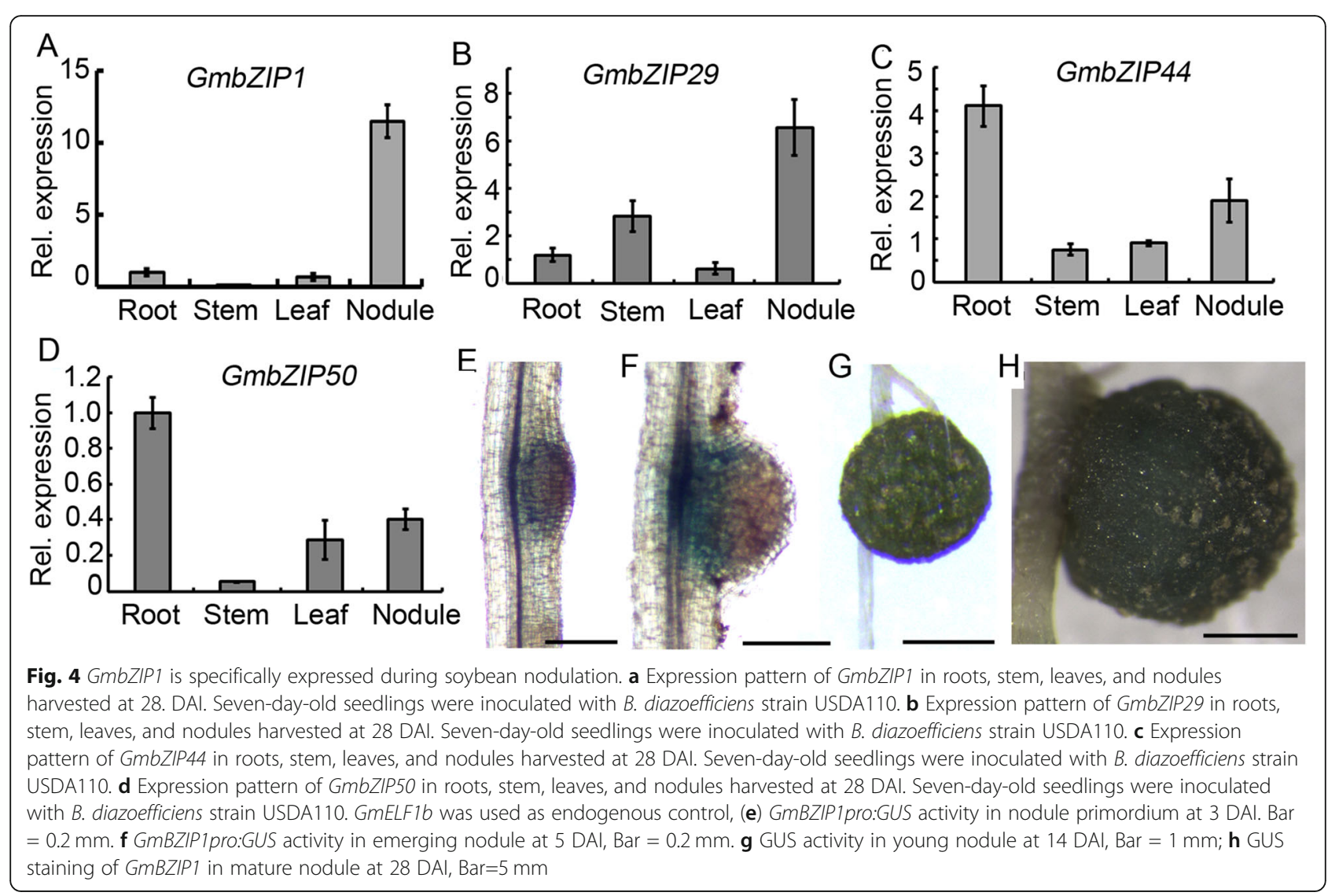

observed at the base of emerging nodule (Fig. 4f), and GUS activity remained high in young nodule and mature nodules (Fig. $4 \mathrm{~g}$ and $\mathrm{h}$ ). These observations indicate that GmbZIP1 expression is activated during nodule formation and nodule development.

\section{GmbZIP1 is responsive to $A B A$ and Positively regulates plant response to $A B A$}

It has been previously shown that GmbZIP1 was induced by ABA in G. $\max$ L. cv. Tiefeng 8 and GmbZIP1 overexpression in Arabidopsis resulted in increased ABA sensitivity of plants [50]. To see if GmbZIP1 in Williams 82 is also ABA responsive, we analyzed the promoter of GmbZIP1 from Williams 82 and found one ABRE cis elements in the $1507 \mathrm{bp}$ (CACGT) upstream of ATG (Supplemental Fig. 1), suggesting that GmbZIP1 expression may be regulated by ABA. Further qPCR assay results confirmed that GmbZIP1 expression was indeed induced by ABA in 5 day-old soybean seedlings (Fig. 5a).

To investigate whether GmbZIP1 in Williams 82 has the conserved function in plant ABA response, we compared the coding sequences of GmZIP1 genes between Tiefeng 8 and Williams 82 , and found only six nucleotide difference between Tiefeng 8 and Williams 82 GmbZIP1s, which causes only four amino acid difference outside of the conserved domains in the corresponding proteins (Supplemental Fig. 2). To see whether the function of the GmbZIP1 from Williams 82 in ABA response remains unchanged, we also ectopically overexpressed GmbZIP1-GFP under control of the CaMV $35 \mathrm{~S}$ promoter in Arabidopsis. As shown in Fig. 5b, high intensity of GFP signal was observed in nucleus of GmbZIP1-GFP transgenic root cells, suggesting that GmbZIP1 was successfully expressed in Arabidopsis (GmbZIP1OE) and GmbZIP1 is a nuclear protein. We then tested the ABA sensitivity of the Arabidopsis plants overexpressing GmbZIP1. In the absence of ABA, the rates of seed germination and cotyledon greening of GmbZIP1OE plant were similar to that of the wild type (Fig. $5 \mathrm{c}$ and e). By contrast, in the presence of $\mathrm{ABA}$, both seed germination and cotyledon greening rates of GmbZIP1OE plant were significantly lower than that of wild type (Fig. $5 \mathrm{~d}$ and f), suggesting that ectopic expression of GmbZIP1 resulted in increased ABA sensitivity of Arabidopsis plants. ABA is a key regulator of plant drought tolerance [56]. To see whether GmbZIP1 affects plant response to drought stress, we also evaluated drought tolerance of GmbZI$P 1 O E$ plants after withdrawing water and rehydration. Survival rate of GmbZIP1OE plants under drought conditions was much higher than that of wild type 

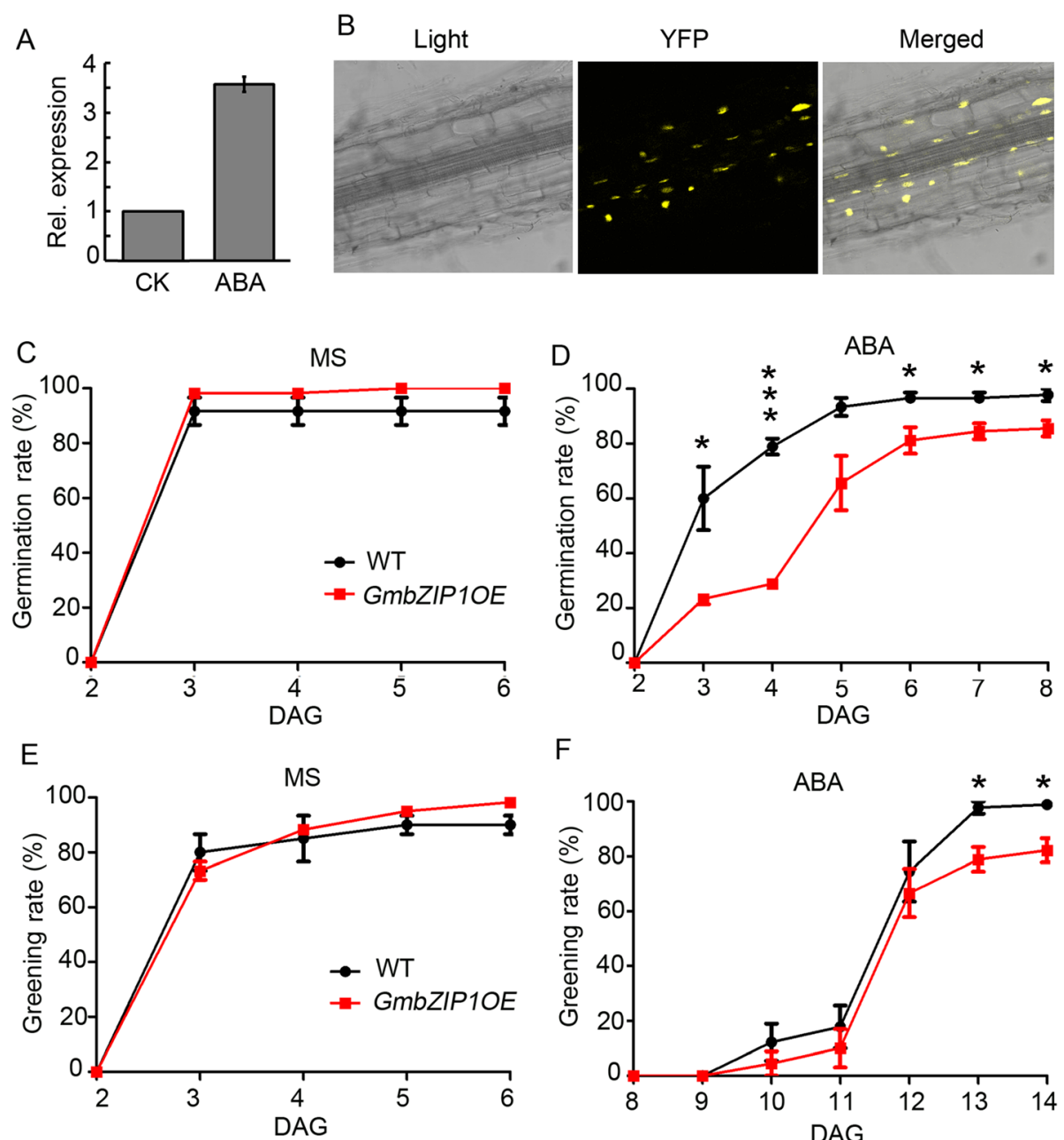

$\mathrm{F}$

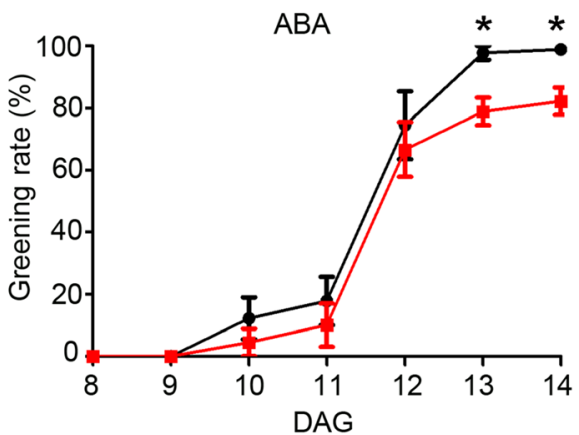

Fig. $5 \mathrm{GmbZIP1}$ is responsive to ABA. a qRT-PCR analysis of expression of GmbZIP1 in the response to ABA. Five-day-old seedlings of soybean were treated with $20 \mu \mathrm{M}$ ABA for three hours. GMELF1b was used as an endogenous control for gene expression. The expression levels are shown as the means \pm SDs from three replicates. $\mathbf{b}$ The subcellular localization analysis of GmbZIP1. GmbZIP1 was fused to YFP and expressed in Arabidopsis. c Germination rates of wild type and GmbZIP1 overexpression line on MS. d Germination rates of wild type and GmbZIP1 overexpression line on MS supplemented with $0.5 \mu \mathrm{M}$ ABA. ${ }^{*} P<0.05$, ${ }^{* *} P<0.001$. e Greening rates of wild type and GmbZIP1 overexpression line on MS. f Greening rates of wild type and GmbZIP1 overexpression line on MS supplemented with $0.5 \mu \mathrm{M} \mathrm{ABA.} \mathrm{*} P<0.05$

(Supplemental Fig. 3), which is consistent with the previous result about a role of GmbZIP1 in drought tolerance [50]. Taken together, these results demonstrate that GmbZIP1 in Williams 82 is a positive regulator of plants in response to $\mathrm{ABA}$ response.

\section{GmbZIP1 negatively regulates Rhizobial infection and nodule number}

The next immediate question is whether GmbZIP1 functions in rhizobial infection and nodule organogenesis in soybean. To do this, we generated transgenic composite plants overexpressing GmbZIP1 under the control of the ubiquitin promoter (UBQ::GmbZIP1) (Fig. 6a), and examined the influence of GmbZIP1 overexpression on root hair deformation and nodule number at early and late stages of nodulation. As shown in the result (Fig. 6b and $\mathrm{c}$ ), the number of the deformed root hairs in $U B Q::$ GmbZIP1 hairy roots was enormously decreased compared with that in empty vector control at $7 \mathrm{DAI}$, suggesting a crucial role of GmbZIP1 in early stage of rhizobial infection. We then scored the nodule number at $14 \mathrm{DAI}$, and found that the transgenic hairy roots overexpressing GmbZIP1 produced fewer nodules than the empty vector control (Fig. 6d-f, Supplemental Fig. 4). These data reveal a negative role of GmbZIP1 in rhizobial infection and nodule development.

\section{GmbZIP1 directly binds and represses expression of GmENOD40-1}

To see whether GmbZIP1 inhibits rhizobial infection and nodule development through the nodulation signaling pathway, we analyzed the effect of GmbZIP1 

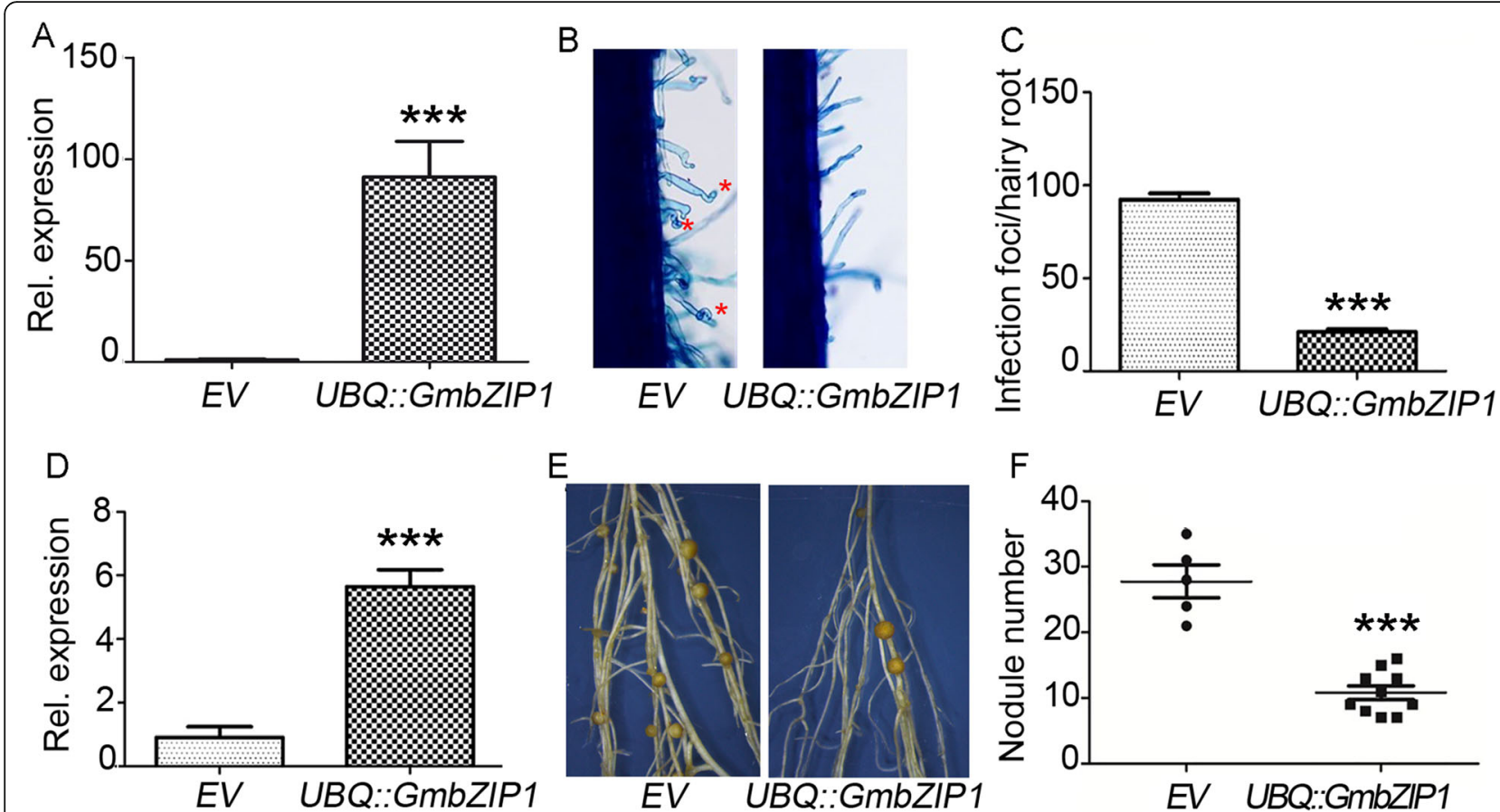

Fig. $6 \mathrm{GmbZIP1}$ overexpression inhibits soybean nodulation. a qRT-PCR analysis of GmbZIP1 expression in transgenic empty or UBQ::GmbZIP1 roots at $7 \mathrm{DAl}$. Values are mean $\pm \mathrm{SD}, p<0.001$. b Infection foci of individual hairy roots expressing the empty vector and UBQ::GmbZIP1. At 7 DAl, $2-\mathrm{cm}$ root segments of hairy roots overexpressing GmbZIP1 below the root-hypocotyl junction were cut and stained with $1 \%(\mathrm{w} / \mathrm{V})$ methylene blue. Considerably deformed root hairs were counted. The asterisk marks the curled root hair; c Quantitative analysis of the infection foci number per hairy root expressing empty vector or UBQ::GmbZIP1 at 7 DAI. Values are mean \pm SD, p<0.001. d qRT-PCR analysis of GmbZIP1 expression in transgenic empty vector or UBQ::GmbZIP1 roots at 14 DAI. Values are mean \pm SD, $p<0.001$. e, $\mathbf{f}$ Overexpression of GmbZIP1 decreased the number of nodulation. The nodule number was counted at 14 DAl of empty vector and UBQ::GmbZIP1

overexpression on the well-known nodulation marker gene GmENOD40-1 using qPCR [57]. Intriguingly, the expression level of GmENOD40-1 in the $U B Q:$ : GmbZIP1 transgenic roots was substantially reduced compared to the vector control at 14 DAI (Fig. 7a). This result indicates that GmbZIP1 modulates soybean nodulation through the nodulation signaling pathway.

GmbZIP1 is a putative transcription factor and we speculated that GmbZIP1 may directly bind to the promoter of GmENOD40-1 and repress its expression or downregulates GmENOD40-1 by targeting the upstream positive regulators in the nodulation pathway. To this end, we first analyzed cis elements in the $3 \mathrm{~kb} G m E$ NOD40-1 promoter. Interestingly, there was one AREB cis element in the promoter of GmENOD40-1 (911 bp upstream of ATG) (Fig. 7b), suggesting a possible interaction between GmbZIP1 protein and the GmENOD401 promoter. To prove the binding of GmbZIP1 to the GmENOD40-1 promoter, we performed a DNA electrophoretic mobility shift assay (EMSA). For this, we expressed and purified the DNA binding domain of GmbZIP1 fused with a His tag in Escherichia coli. The result showed that the GmbZIP1-His fusion protein was able to bind to the DNA probes containing the AREB cis-element at the regions of the GmENOD40-1 promoter (Fig. 7c, Supplemental Fig. 5). In a competition assay, the binding of GmbZIP1-His to the labeled DNA probe was reduced significantly by an excess amount of biotin-unlabeled DNA probe (Fig. 7c, Supplemental Fig. 5), suggesting that the interaction between GmbZIP1 and the GmENOD40-1 promoter was specific. Collectively, these data suggest that GmBZIP1 regulates ABA-mediated nodulation inhibition by directly targeting GmENOD40-1 and repressing its transcription.

\section{Discussion}

Symbiotic nodulation is a complex trait that is precisely regulated by endogenous cues and environmental conditions. Phytohormones play an integral role in overall nodulation. Auxin and cytokinin positively regulate nodulation, while others negatively regulate nodulation. Therefore, dynamic hormonal balance is crucial to optimal and successful interaction between rhizobia and plants and nodule formation [36]. It has been shown that ABA application inhibits both indeterminate and determinate nodules in legumes [33, 35, 46]. However, how ABA regulates nodulation, in particular how ABA signaling interplays with nodulation signaling remains elusive. 


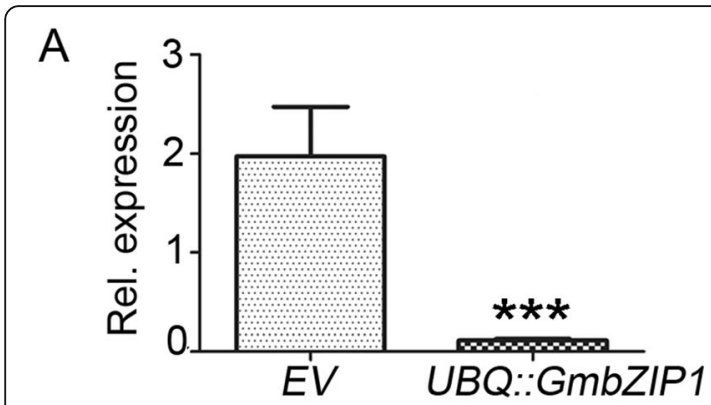

B
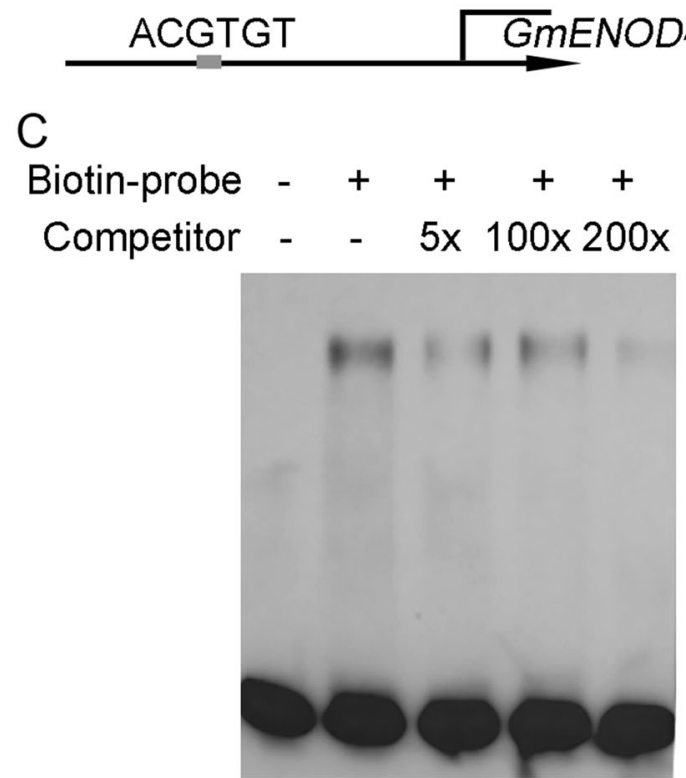

Fig. 7 GmbZIP1 binds and represses GmENOD40-1 expression. a qRT-PCR analysis of GmENOD40-1 expression in transgenic empty or UBQ::GmbZIP1 overexpression roots at 14 DAl. Values are mean \pm SD, $p<0.001$. b Schematic representation of GmENOD40-1 locus. The GmENOD40-1 promoter was shown as a line and the ACGT motif (ACGTGT) was shown as grey box. c EMSA for DNA binding domain of GmbZIP1 fused with a His tag to oligo-DNAs containing ACGTGT. Biotin-labeled probe was incubated with GmbZIP1-His. Competition for binding was performed with different concentration of unbiotinlabeled probe. The experiments were repeated for three times, and the representative results were shown

In this study, we showed that nodulation is the most sensitive process during plant growth and development; we identified GmbZIP1 as positive regulator of ABA response but negative regulator in soybean nodulation; and most importantly, we revealed that GmbZIP1 inhibits nodulation through directly repressing $G m E$ NOD40-1 expression.

ABA is a key regulator of plant growth and development [56]. In soybean, we found that exogenous ABA has diverse roles on shoot growth, lateral root development and nodulation. Low level of ABA stimulated shoot growth, while high level of ABA inhibited growth of shoot. In comparison, lateral roots were insensitive to
ABA in lower ABA concentration, and high concentration of ABA promoted lateral root development. Interestingly, root nodule exhibited extremely sensitivity to $\mathrm{ABA}$ and ABA treatment reduced nodule number in a dose-dependent manner. Notably, nodulation inhibition mediated by ABA in soybean is specific, as the low concentration ABA $(0.5 \mu \mathrm{M})$ was sufficient to inhibit nodulation but had no effect on shoot and root growth (Fig. 1e). Exogenous ABA can interrupt rhizobia-induced root hair deformation and nodule number in soybean, supporting the notion that during nodulation, ABA mainly exerts its negative regulatory role in early stage of nodulation including rhizobial infection and nodule formation as proposed before in M. trunctula and L. japonicum $[33,35]$. It is conceivable that the hypersensitivity of early nodulation to ABA is a conserved mechanism for attenuating nodulation signaling to maintain optimal nodule number in legumes.

Nodulation signaling pathway is responsible for rhizibial infection and nodule formation. It has been proposed that ABA inhibits rhizobial infection and nodule initiation through suppressing upstream signaling nodes in epidermis and activation of nodule formation genes, such as ENOD11 gene [35]. Consistent with this, our results showed that ABA exerts its inhibitory role through a similar mechanism in soybean. For example, the induction of GmENOD40-1 in soybean nodule formation was significantly reduced by ABA treatment (Fig. 2d). ABA regulates various biological processes mainly through ABA signaling. The previous results have identified Sensitivity to ABA 1(STA-1) as a key ABA-mediated suppressor of the initiation of Nod factor signaling in Medicago [35], although the underlying molecular mechanism is not yet clear. However, the gene that mediates ABA-induced inhibition of nodule formation and its action remains completely unknown. Here, we provide several pieces of evidence to show that AREB transcription factor GmbZIP1 is a repressor of $G m E$ NOD40-1 to suppress nodule initiation induced by ABA.

AREB family proteins are key transcription factors in the ABA signaling pathway that regulate plant responses to ABA by targeting many genes related to plant growth and stress tolerance $[44,45]$. Firstly, we found that among the ABA-related AREB/ABF genes in soybean, GmbZIP1 is specifically expressed in nodule primorida and nodule (Fig. 4). Secondly, we proved that GmbZIP1 is a positive regulator of plant ABA response. GmbZIP1 is induced by ABA and ectopic expression of GmbZIP1 increased ABA sensitivity of plant during early development and drought tolerance in Arabidopsis (Fig. 5, Supplemental Fig. 3). Thirdly, we demonstrated that GmbZIP1 negatively regulates soybean nodulation as overexpression of GmbZIP1 resulted in reduced number 
of root hair deformation and nodules (Fig. 6). Finally, we showed that GmbZIP1 can directly bind to the AREB element in the GmENOD40-1 promoter to repress its expression (Fig. 7). It is possible that rhizobia induces ABA to activate GmbZIP1 expression in cortex cells, which in turn represses GmENOD40-1 expression resulting in suppression of nodule formation. Since GmbZIP1 is expressed in other stages of nodulation and GmbZIP1 overexpression can also affect root hair deformation, we do not exclude the possibility that GmbZIP1 regulates ABA-mediated other processes during nodulation. Since GmbZIP1 is responsive and mediates plant response to abiotic stress [50], it is also possible that GmbZIP1 mediates nodulation under abiotic stress.

\section{Conclusion}

In summary, our data have identified a key component GmbZIP1 in ABA signaling of soybean that plays a negative role in soybean nodulation. Intriguingly, our findings reveal a novel mechanism by which GmbZIP1 mediates crosstalk between the ABA and NF signal transduction pathways during nodule initiation. Considering high level of conservation in ABA-mediated nodulation inhibition and bZIP1 transcription factor in legumes, our findings provide novel insights into elucidation of ABA regulation of symbiotic nodulation.

\section{Methods}

Plant and rhizobia growth, hairy root transformation, and B. diazoefficiens inoculation

Soybean [G. $\max ($ L.) Merrill cv. Williams 82] was used to clone and analyze the function of GmbZIP1. The seeds were obtained from Lab of Prof. Tianfu Han (Chinese Academy of Agricultural Sciences). Soybean seedlings were cultured in a growth room at $25-26^{\circ} \mathrm{C}$ and $16 \mathrm{~h} / 8 \mathrm{~h}$ light/dark conditions. For soybean hairy root transformation, healthy and uniform soybean seeds were planted in soil for 3 days in growth room. Germinating seedlings were used for hairy root transformation with Agrobacterium rhizogenes strain K599 containing various constructs as described previously [58]. For nodulation phenotype assays, the putative transgenic plants were transplanted to pots containing vermiculite and grown for 1 week to allow rooting. They were then inoculated with $30 \mathrm{ml}$ suspension of $B$. diazoefficiens USDA110 (OD600 $=0.08)$ as described previously [58]. The individual root and the nodules were collected for molecular characterization of the transgenic roots and for nodule number quantification at the indicated time points (days after infection, DAI). Shanshan Song and Shimin $\mathrm{Xu}$ undertook the formal identification of the plant material used in this study and the material used in this study didn't deposited in publicly available herbarium.

\section{ABA treatment}

For ABA treatments, the experiments were done according to the Jone et al. (Jones et al., 2013) with minor modifications. Briefly, the soybean was germinated on medium containing 7\% agar for 6 days. The plants were then transferred on plants containing Jensen's medium $\left(\mathrm{CaHPO}_{4} 1 \mathrm{~g} / \mathrm{L}, \mathrm{MgSO}_{4} .7 \mathrm{H}_{2} \mathrm{O} 0.2 \mathrm{~g} / \mathrm{L}, \mathrm{K}_{2} \mathrm{HPO}_{4} 0.2 \mathrm{~g} / \mathrm{L}\right.$, $\mathrm{NaCl} \quad 0.2 \mathrm{~g} / \mathrm{L}, \quad \mathrm{FeCl}_{3} .6 \mathrm{H}_{2} \mathrm{O} \quad 0.1 \mathrm{~g} / \mathrm{L}, \quad \mathrm{H}_{3} \mathrm{BO}_{3} 1 \mathrm{mg} / \mathrm{L}$, $\mathrm{ZnSO}_{4} .7 \mathrm{H}_{2} \mathrm{O} \quad 1 \mathrm{mg} / \mathrm{L}, \quad \mathrm{CuSO}_{4} .5 \mathrm{H}_{2} \mathrm{O} \quad 0.5 \mathrm{mg} / \mathrm{L}$, $\mathrm{MnCl}_{2} .4 \mathrm{H}_{2} \mathrm{O} \quad 0.5 \mathrm{mg} / \mathrm{L}, \mathrm{NaMnO}_{4} .2 \mathrm{H}_{2} \mathrm{O} 1 \mathrm{mg} / \mathrm{L}$, agar $11.5 \mathrm{mg} / \mathrm{L})$ supplemented with different concentrations of $\mathrm{ABA}$ with roots on the plates and the shoots out of the plate. The plants were inoculated with suspension of B. diazoefficiens USDA110 $\left(\mathrm{OD}_{600}=0.1\right)$. The plants were cultured in growth room and the plates were wrapped with silver paper to keep root in dark. 18 days later, the nodule number, shoot and root phenotype were analyzed.

\section{Curled root hair assays}

In order to examine the early infection events, the root segments $(4 \mathrm{~cm})$ below the hypocotyl-root junctions were cut from the transformed hairy roots at 7 DAI. The root fragments were rinsed briefly in sterile PBS buffer and stained with $0.01 \%$ methylene blue for $15 \mathrm{~min}$ and then washed three times with deionized water as described previously [57]. The stained transgenic roots were observed with a Leica biological microscope. The root hairs with tight curls were counted and referred to as 'Infection foci'.

\section{RNA extraction and quantitative PCR analysis}

Total RNA was extracted from wild type or composite plants using Trizol reagent according to the manufacturer's protocol (Tiangen Biotech Co., Ltd., Beijing, China). The total RNA samples were treated with DNase I (Invitrogen) to remove contaminating genomic DNA and first-strand cDNA was synthesized using a FastQuant RT Kit (Tiangen Biotech). Quantitative polymerase chain reactions (qPCR) were performed using SuperReal PreMix Plus (SYBR Green; Tiangen Biotech). GmELF1B was used as the internal reference gene [57].

\section{Vector construction}

For the overexpression construct of GmbZIP1, the full length GmbZIP1 was cloned and inserted into the vector pUBI:pCAMBIA1301 using the restriction enzymes $X b a \mathrm{I} / B a m H I$; For the GmbZIP1 promoter: GUS reporter construct, the putative promoter region $(2.0 \mathrm{~kb})$ of GmbZIP1 was amplified from cv. Williams 82 genomic 
DNA and inserted into the vector pCAMBIA1391 using the restriction enzymes EcoRI/BamHI.

\section{EMSA}

Electrophoretic Mobility Shift Assays (EMSAs) were performed using the Light Shift Chemiluminescent EMSA Kit (Pierce) according to the manufacturer's protocol and as described by Wang et al. [57]. For the GmbZIP1His construct, the coding sequence of the DNA binding domain of GmbZIP1 (901-1320 bp) was amplified and inserted into pET22b using NdeI/HindIII. The probebinding activity of the protein was analyzed using oligonucleotides labeled with biotin at the 5'end (Sangon, China). After incubation at room temperature for 30 $\mathrm{min}$, the protein-probe mixture was separated on a $6 \%$ polyacrylamide gel and transferred to a Biodyne B nylon membrane (Pall). Migration of the biotin-labeled probes was detected using streptavidin-horseradish peroxidase conjugates that bind to biotin and the chemiluminescent substrate according to the manufacturer's protocol.

\section{Statistical analysis}

The data including gene expression and phenotypic analysis in this study were analyzed using GraphPad Prism 5 (GraphPad Software, Inc., La Jolla, CA). The averages and Standard Deviations (SDs) of the data were calculated, and one-way ANOVA Student's $t$ test were performed to generate $p$ values.

\section{Supplementary Information}

The online version contains supplementary material available at https://doi. org/10.1186/s12870-020-02810-9.

Additional file 1:. Supplementary information contains Supplementary Fig. S1-S3.

\section{Abbreviations \\ ABA: Abscisic acid; ABF: ABRE binding factor; ABRE: ABA-responsive element; bZIP: Basic region/leucine zipper; CCaMK: Calmodulin-dependent Kinase; CK: Cytokinin; CNGC15: Nuclear-localized cyclic nucleotide-gated channels; DMI1: Does Not Make Infections 1; ENOD11: Early Nodulin 11; ERN1: Ethylene Response Factor Required for Nodulation1; JA: Jasmonate; NF: Nod factor; NFR: NF receptor; NIN: Nodule Inception; PP2C: Group A protein type 2C phosphatases; RIP: Rhizobium-induced Peroxidase; SA: Salicylic acid; SnRK2s: Sucrose nonfermenting-1-related protein kinase class 2.}

\section{Acknowledgments}

We thank Prof. Tianfu Han (Chinese Academy of Agricultural Sciences) for gifting W82 seeds.

\section{Authors' contributions}

ZW and XL conceived the study and designed the experiments; SX, SS, XD, $J W, X W$ and $X W$ performed the experiments; RZ, JL, HY, XW, ZW and XL analyzed the data; $Z W$ and $X L$ wrote the manuscript with input from all of the authors. All authors have read and approved the manuscript.

\section{Funding}

This work was supported by grants from the National Key Research and Development Program of China (2016YFA0500503), the National Natural Science Foundation of China (31730066), Huazhong Agricultural University
Scientific \& Technological Self-innovation Foundation (2015RC014) and Fundamental Research Funds for Central Universities (2662018PY075). The funder had no role in study design, data collection and analysis, decision to publish, or preparation of the manuscript.

\section{Availability of data and materials}

All data generated or analysed during this study are included in this published article and its supplementary information files. The datasets used and/or analysed during the current study are available from the corresponding author on reasonable request.

Ethics approval and consent to participate

Not applicable.

\section{Consent for publication}

Not applicable.

\section{Competing interests}

The authors declare that they have no competing interests.

Received: 28 August 2020 Accepted: 22 December 2020

Published online: 09 January 2021

\section{References}

1. Ferguson BJ, Indrasumunar A, Hayashi S, Lin MH, Lin YH, Reid DE, et al. Molecular analysis of legume nodule development and autoregulation. J Integr Plant Biol. 2010;52:61-76.

2. Desbrosses GJ, Stougaard J. Root nodulation: a paradigm for how plantmicrobe symbiosis influences host developmental pathways. Cell Host Microbe. 2011;10:348-58.

3. Downie JA. Legume nodulation. Curr Biol. 2014;24:R184-90.

4. Lerouge $P$, Roche P, Faucher C, Maillet F, Truchet G, Promé JC, et al. Symbiotic host-specificity of rhizobium meliloti is determined by a sulphated and acylated glucosamine oligosaccharide signal. Nature. 1990; 344:781-4.

5. Sanjuan J, Carlson RW, Spaink HP, Bhat UR, Barbour WM, Glushka J, et al. G. a 2-O-methylfucose moiety is present in the lipo-oligosaccharide nodulation signal of Bradyrhizobium japonicum. Proc Natl Acad Sci U S A. 1992;89:878993.

6. Oldroyd GE. Speak friend, and enter: signalling systems that promote beneficial symbiotic associations in plants. Nat Rev Microbiol. 2013;11:25263.

7. Madsen EB, Madsen LH, Radutoiu S, Olbryt M, Rakwalska M, Szczyglowski K, et al. A receptor kinase gene of the LysM type is involved in legume perception of rhizobial signals. Nature. 2003;425:637-40.

8. Radutoiu S, Madsen LH, Madsen EB, Felle HH, Umehara $Y$, Grønlund M, et al. Plant recognition of symbiotic bacteria requires two LysM receptor-like kinases. Nature. 2003:425:585-92.

9. Arrighi JF, Barre A, Ben Amor B, Bersoult A, Soriano LC, Mirabella R, et al. The Medicago truncatula lysin motif-receptor-like kinase gene family includes NFP and new nodule-expressed genes. Plant Physiol. 2006;142: 265-79.

10. Indrasumunar A, Kereszt A, Searle I, Miyagi M, Li D, D T Nguyen C, Men A, et al. Inactivation of duplicated Nod Factor Receptor 5 (NFR5) genes in recessive loss-of-function non-nodulation mutants of allotetraploid soybean (Glycine max L. Merr.). Plant Cell Physiol. 2009;51:201-14.

11. Indrasumunar A, Searle I, Lin MH, Kereszt A, Men A, Carroll BJ, et al. Nodulation factor receptor kinase 1a controls nodule organ number in soybean (Glycine max L. Merr). Plant J. 2011;65:39-50.

12. Ané JM, Kiss GB, Riely BK, Penmetsa RV, Oldroyd GE, Ayax C, et al. Medicago truncatula DMI1 required for bacterial and fungal symbioses in legumes. Science. 2004;303:1364-7.

13. Hogg BV, Cullimore JV, Ranjeva R, Bono JJ. The DMII and DMI2 early symbiotic genes of medicago truncatula are required for a high-affinity nodulation factor-binding site associated to a particulate fraction of roots. Plant Physiol. 2006;140:365-73.

14. Charpentier M, Sun J, Vaz Martins T, Radhakrishnan GV, Findlay K, Soumpourou E, et al. Nuclear-localized cyclic nucleotide-gated channels mediate symbiotic calcium oscillations. Science. 2016;352:1102-5. 
15. Liu J, Miller SS, Graham M, Bucciarelli B, Catalano CM, Sherrier DJ, et al. Recruitment of novel calcium-binding proteins for root nodule symbiosis in Medicago truncatula. Plant Physiol. 2006;141:167-77.

16. Singh S, Katzer K, Lambert J, Cerri M, Parniske M. Cyclops, a DNA-binding transcriptional activator, orchestrates symbiotic root nodule development. Cell Host Microbe. 2014;15:139-52.

17. Smit P, Raedts J, Portyanko V, Debellé F, Gough C, Bisseling T, et al. NSP1 of the GRAS protein family is essential for rhizobial Nod factor-induced transcription. Science. 308:1789-91.

18. Murakami Y, Miwa H, Imaizumi-Anraku H, Kouchi H, Downie JA, Kawaguchi $\mathrm{M}$, et al. Positional cloning identifies Lotus japonicus NSP2, a putative transcription factor of the GRAS family, required for NIN and ENOD40 gene expression in nodule initiation. DNA Res. 2006;13:255-65.

19. Battaglia M, Rípodas C, Clúa J, Baudin M, Aguilar OM, Niebel A, et al. A nuclear factor $Y$ interacting protein of the GRAS family is required for nodule organogenesis, infection thread progression, and lateral root growth. Plant Physiol. 2014;164:1430-42.

20. Cerri MR, Frances L, Kelner A, Fournier J, Middleton PH, Auriac MC, et al. The symbiosis-related ERN transcription factors act in concert to coordinate rhizobial host root infection. Plant Physiol. 2016;171:1037-54.

21. Cerri MR, Wang Q, Stolz P, Folgmann J, Frances L, Katzer K, et al. The ERN1 transcription factor gene is a target of the CCaMK/CYCLOPS complex and controls rhizobial infection in Lotus japonicus. New Phytol. 2017;215:323-37.

22. Cerri MR, Frances L, Laloum T, Auriac MC, Niebel A, Oldroyd GE, et al. Medicago truncatula ERN transcription factors: regulatory interplay with NSP1/NSP2 GRAS factors and expression dynamics throughout Rhizobial infection. Plant Physiol. 2012;160:2155-72.

23. Hirsch S, Kim J, Muñoz A, Heckmann AB, Downie JA, Oldroyd GE. GRAS proteins form a DNA binding complex to induce gene expression during nodulation signaling in Medicago truncatula. Plant Cell. 2009;21:545-57.

24. Gonzalez-Rizzo S, Crespi M, Frugier F. The Medicago truncatula CRE1 cytokinin receptor regulates lateral root development and early symbiotic interaction with Sinorhizobium meliloti. Plant Cell. 2006;18:2680-93.

25. Murray JD, Karas BJ, Sato S, Tabata S, Amyot L, Szczyglowski K. A cytokinin perception mutant colonized by rhizobium in the absence of nodule organogenesis. Science. 2007;315:101-4.

26. Tirichine L, Sandal N, Madsen LH, Radutoiu S, Albrektsen AS, Sato S, et al. A gain-of-function mutation in a cytokinin receptor triggers spontaneous root nodule organogenesis. Science. 2007;315:104-7.

27. Plet J, Wasson A, Ariel F, Le Signor C, Baker D, Mathesius U, et al. MtCRE1dependent cytokinin signalling integrates bacterial and plant cues to coordinate symbiotic nodule organogenesis in Medicago truncatula. Plant J. 2001;65:622-33

28. Ng JL, Hassan S, Truong TT, Hocart CH, Laffont C, Frugier F, et al. Flavonoids and auxin transport inhibitors rescue symbiotic nodulation in the Medicago truncatula cytokinin perception mutant cre1. Plant Cell. 2015;27:2210-26.

29. Cai Z, Wang Y, Zhu L, Tian Y, Chen L, Sun Z, et al. GmTIR1/GmAFB3-based auxin perception regulated by miR393 modulates soybean nodulation. New Phytol. 2017;215:672-86.

30. Ryu H, Cho H, Choi D, Hwang I. Plant hormonal regulation of nitrogenfixing nodule organogenesis. Mol Cell. 2012;34:117-26.

31. Cutler SR, Rodriguez PL, Finkelstein RR, Abrams SR. Abscisic acid: emergence of a core signaling network. Annu Rev Plant Biol. 2010;61:651-79.

32. Cho MJ, Harper JE. Effect of abscisic acid application on root isoflavonoid concentration and nodulation of wild type and nodulation-mutant soybean plants. Plant Soil. 1993;153:145-9.

33. Suzuki A, Akune $M$, Kogiso M, Imagama Y, Osuki Kl, Uchiumi T, et al. Control of nodule number by the phytohormone abscisic acid in the roots of two leguminous species. Plant Cell Physiol. 2004;45:914-22.

34. Lin J, Frank M, Reid D. No home without hormones: how plant hormones control legume nodule organogenesis. Plant Commun. 2020. https://doi. org/10.1016/j.xplc.2020.100104

35. Ding Y, Kalo P, Yendrek C, Sun J, Liang Y, Marsh JF, et al. Abscisic acid coordinates nod factor and cytokinin in signaling during the regulation of nodulation in Medicago truncatula. Plant Cell. 2008;20:2681-95.

36. Liu H, Zhang C, Yang J, Yu N, Wang E. Hormone modulation of legumerhizobial symbiosis. J Integr Plant Biol. 2018;60:632-48.

37. Hubbard KE, Nishimura N, Hitomi K, Getzoff ED, Schroeder JI. Early abscisic acid signal transduction mechanisms: newly discovered components and newly emerging questions. Genes Dev. 2010;24:1695-708.
38. Ma Y, Szostkiewicz I, Korte A, Moes D, Yang Y, Christmann A, et al. Regulators of PP2C phosphatase activity function as abscisic acid sensors. Science. 2009;324:1064-8.

39. Melcher K, Ng LM, Zhou XE, Soon FF, XU Y, Suino-Powell KM, et al. A gatelatch-lock mechanism for hormone signalling by abscisic acid receptors. Nature. 2009;462:602-8.

40. Takahashi M, Zhi Y, Fujita Y, Yoshida T, Kodaira KS, Yamaguchi-Shinozaki K, et al. Structural basis of abscisic acid signalling. Nature. 2009;462:609-14.

41. Park SY, Fung P, Nishimura N, Jensen DR, Fujii H, Zhao Y, et al. Abscisic acid inhibits type $2 \mathrm{C}$ protein phosphatases via the PYR/PYL family of START proteins. Science. 2009;324:1068-71.

42. Soon FF, Ng LM, Zhou XE, West GM, Kovach A, Tan MH, et al. Molecular mimicry regulates ABA signaling by SnRK2 kinases and PP2C phosphatases. Science. 2012;335:85-8.

43. Nakashima K, Ito Y, Yamaguchi-Shinozaki K. Transcriptional regulatory networks in response to abiotic stresses in Arabidopsis and grasses. Plant Physiol. 2009;149:88-95.

44. Fujita Y, Fujita M, Shinozaki K, Yamaguchi-Shinozaki K. ABA mediated transcriptional regulation in response to osmotic stress in plants. J Plant Res. 2011;124:509-25.

45. Yoshida T, Fujita Y, Maruyama K, Mogami J, Todaka D, Shinozaki K, et al. Four Arabidopsis AREB/ABF transcription factors function predominantly in gene expression downstream of SnRK2 kinases in abscisic acid signalling in response to osmotic stress. Plant Cell Environ. 2015:38:35-49.

46. Bano A, Harper JE. Plant growth regulators and phloem exudates modulate root nodulation of soybean. Funct Plant Biol. 2002;29:1299-307.

47. Bano A, Harper JE, Auge RM, Neuman DS. Changes in phytohormone levels following inoculation of two soybean lines differing in nodulation. Funct Plant Biol. 2002;29:965-74

48. Choudhury Roy S, Johns SM, Pandey S. A convenient, soil-free method for the production of root nodules in soybean to study the effects of exogenous additives. Plant Direct. 2019;3:e00135

49. Zhang M, Liu Y, Shi H, Gu M, Chai M, He Q, et al. Evolutionary and expression analyses of soybean basic Leucine zipper transcription factor family. BMC Genomics. 2018;19:159.

50. Gao SQ, Chen M, Xu ZS, Zhao CP, Li L, Xu HJ, et al. The soybean GmbZIP1 transcription factor enhances multiple abiotic stress tolerances in transgenic plants. Plant Mol Biol. 2011;75:537-53.

51. Jones KM, Mendis HC, Queiroux C. Single-plant, sterile microcosms for nodulation and growth of the legume plant Medicago truncatula with the rhizobial symbiont Sinorhizobium meliloti. J Vis Exp. 2013;80:e50916.

52. Dröge-Laser W, Snoek BL, Snel B, Weiste C. The Arabidopsis bZIP transcription factor family-an update. Curr Opin Plant Biol. 2018;45:36-49.

53. Ji H, Wang S, Cheng C, Li R, Wang Z, Jenkins Gl, et al. The RCC1 family protein $S A B 1$ negatively regulates $A B 15$ through multidimensional mechanisms during postgermination in Arabidopsis. New Phytol. 2019;222: 907-22.

54. Severin AJ, Woody JL, Bolon YT, Joseph B, Diers BW, Farmer AD, et al. RNASeq atlas of Glycine max: a guide to the soybean transcriptome. BMC Plant Biol. 2010;10:160.

55. Lopez-Molina L, Mongrand S, Chua NH. A postgermination developmental arrest checkpoint is mediated by abscisic acid and requires the $\mathrm{ABI} 5$ transcription factor in Arabidopsis. Pro Nati Acad Sci U S A. 2001;98:4782-7.

56. Zhu JK. Salt and drought stress signal transduction in plants. Annu Rev Plant Biol. 2002:53:247-73.

57. Wang Y, Wang L, Zou Y, Chen L, Cai Z, Zhang S, et al. Soybean miR172C targets the repressive AP2 transcription factor NNC1 to activate ENOD40 expression and regulate nodule initiation. Plant Cell. 2014;26:4782-801.

58. Wang Y, Li P, Cao X, Wang X, Zhang A, Li X. Identification and expression analysis of miRNAs from nitrogen-fixing soybean nodules. Biochem Biophys Res Commun. 2009:378:799-803.

\section{Publisher's Note}

Springer Nature remains neutral with regard to jurisdictional claims in published maps and institutional affiliations. 